\title{
04 \\ BATTERIES NOT INCLUDED: IDENTIFYING DISC BATTERY INJURY IN A HEALTH SETTING
}

doi:10.1136/injuryprev-2012-040590i.4

R Barker. Queensland Injury Surveillance Unit, Mater Health Services, South Brisbane, Queensland, Australia

Background The risk of severe injury and death associated with ingestion or insertion of disc batteries is being recognised by product safety regulators, injury prevention practitioners and specialised clinical health groups worldwide. As prevention efforts step up with public awareness campaigns, there is still a problem in identifying children who have ingested or inserted a disc battery and accessing rapid treatment.

Aims/Objectives/Purpose To describe the challenges in recognising children who have been exposed to a disc battery from the point of view of a parent and a clinician using a clinical example. To describe challenges in identifying cases of disc battery exposure in health data.

Methods The author works as an emergency paediatrician and directs the Queensland Injury Surveillance Unit. The presentation will describe her personal experience of a case of misdiagnosis of an oesophageal disc battery set within the context of injury surveillance data describing the extent of this issue in Queensland.

Results/Outcome The presentation will clarify reasons for underreporting and inform broader discussion about prevention of disc battery related injury. 
Significance/Contribution to the Field This paper is a call for primary prevention as diagnosis is challenging, delays common and the results are potentially fatal. 